\title{
Ventilatory function, height, and mortality among lifelong non-smokers
}

\author{
David P Strachan
}

\begin{abstract}
Study objective-The aims were to determine the relationship between spirometric indices and mortality among lifelong non-smokers, and to investigate whether the association of short stature with increased risk of death is explained by reduced levels of ventilatory function in shorter men.
\end{abstract}

Design-The study was a nested (within cohort) case-control analysis of an 18 year prospective study of mortality.

Subjects-Participants were 3452 male civil servants aged $40-64$ years at entry who denied ever having smoked tobacco.

Measurements and main results -408 men who died were matched to 2874 controls of the same age and height. Reduced one second forced expiratory volume $\left(F^{2} V_{1}\right)$ was associated with mortality from nonrespiratory causes (rate ratio per litre decrease $=1.44,95 \%$ confidence interval 1.19-1·73). The ratio of $\mathrm{FEV}_{1}$ to forced vital capacity was a weak predictor of mortality. Among 397 case-control sets matched for age and $F E V_{1}$, mortality was unrelated to height. Comparing mortality differentials across age adjusted tertiles of each risk factor, height adjusted $F E V_{1}$ was a stronger predictor of death than height, body mass index, or plasma cholesterol. FEV 1 adjusted for age but not for height was almost as strong a predictor as systolic blood pressure.

Conclusions-The determinants of ventilatory function in lifelong nonsmokers may include causes of premature death. FEV 1 may be a more sensitive indicator than height of early life influences upon mortality.

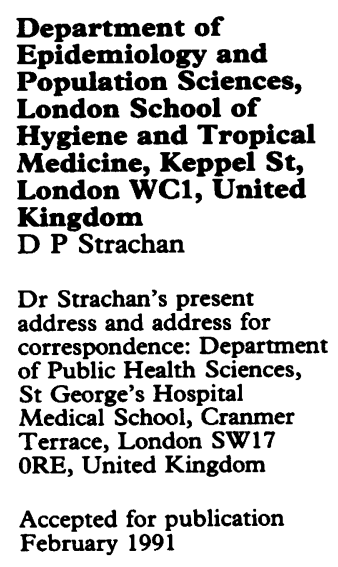

Associations have been described between reduced ventilatory function and subsequent mortality or non-fatal coronary heart disease. ${ }^{1-10}$ These have generally used statistical modelling to control for smoking habit, but because the influence of smoking upon both ventilatory function and mortality is so strong, such adjustment may be inadequate. In such circumstances, residual confounding by smoking would generate a spurious association between diminished lung function and mortality. A recent analysis of the relationship of ventilatory function to coronary heart disease in Hawaii found no association among non-smokers and suggested that the association observed among smokers was explained by residual confounding. ${ }^{11}$
Other studies, however, suggest that a real association may exist. In Baltimore, all cause mortality during 24 years of follow up was significantly and inversely related to $F E V_{1}$ adjusted for age and height among lifelong nonsmokers. ${ }^{12}$ Similar findings have been reported for vital capacity among healthy non-smokers in the Framingham study, ${ }^{13}$ and the Copenhagen City Heart Study ${ }^{14} \mathrm{~A}$ longitudinal study in Papua New Guinea found that the local methods of smoking tobacco were not associated with increased risk of death but that reduced ventilatory function was nevertheless an important predictor of all cause mortality. ${ }^{15}$

Men of short stature are at increased risk of death and coronary heart disease. ${ }^{16-18}$ These associations have attracted considerable interest because height, in so far as it is influenced by environmental factors, is mainly determined during childhood and adolescence. A recent analysis of incident cases of myocardial infarcation in the British Regional Heart Study suggested that the effect of height on risk of myocardial infarcation may be explained by the tendency for short men to have lower levels of ventilatory function. ${ }^{18}$ However, that study included both smokers and non-smokers and therefore could not exclude the possibility that the closer relationship of myocardial infarcation to forced expiratory volume than to height was a reflection of residual confounding by unmeasured aspects of smoking behaviour.

In order to clarify these issues, this paper reports the effect of ventilatory function and height upon 18 year mortality among a large cohort of British civil servants who denied ever having smoked tobacco.

\section{Methods}

The Whitehall study obtained questionnaire information, clinical measurements, and samples of blood from 19018 male civil servants who were examined during 1967-1969. ${ }^{19}$ Subsequent deaths among these men have been identified through the National Health Service Central Register and the underlying cause of death has been coded throughout to the 8th revision of the International classification of diseases. This analysis is limited to deaths occuring on or before 31 January 1987 among men aged 40-64 years at examination who answered negatively to each of the following questions:

1. Do you smoke cigarettes now?

2. If you do not smoke cigarettes now, did you ever smoke them?

3. Have you ever smoked a pipe?

4. Have you ever smoked cigars regularly? 
The examination at entry included measurement of height, weight, and blood pressure (using the London School of Hygiene sphygmomanometer with the subject seated). Three forced expiratory manoeuvres were recorded by Vitalograph spirometer and the means of the highest two measurements of forced expiratory volume in one second $\left(\mathrm{FEV}_{1}\right)$ and the corresponding measurements of forced vital capacity (FVC) were coded for computer analysis. Capillary blood samples were analysed for plasma cholesterol concentration. A standardised history of cardiorespiratory symptoms was obtained by questionnaire. A six limb lead electrocardiogram (ECG) was recorded and classified by the Minnesota code.

Subjects with a history of angina or severe anterior chest pain lasting an hour or more, or abnormal ECG tracings (Minnesota codes for Q/QS waves $1 \cdot 1-1 \cdot 3$, ST depression $4 \cdot 1-4 \cdot 4$, T wave inversion or flattening $5 \cdot 1-5 \cdot 3$, or left bundle branch block $7 \cdot 1$ ) were grouped together as providing evidence of prevalent coronary heart disease at entry to the study.

\section{STATISTICAL ANALYSIS}

Statistical Analysis System (SAS) ${ }^{20}$ was used for data processing. Two "nested" (within cohort) case-control studies were generated. Cases were defined as men dying during the 18 years of follow up. Matched controls were selected for each case from among the men who survived longer than the case from their date of examination. In the first case-control analysis, the matching criteria were age at examination (single years), and height (measured to the nearest half inch $[1.3 \mathrm{~cm}]$ ). In the second, the matching criteria were age (single years) and $\mathrm{FEV}_{1}$ (recorded to the nearest $100 \mathrm{ml}$ ) In each study, all eligible controls were included, resulting in variable numbers of controls per case.

The matched case-control sets were analysed by conditional logistic regression using the Epidemiological Graphics Estimation and Testing package (EGRET). ${ }^{21}$ Case-control status was the outcome variable and measurements of ventilatory function and other cardiovascular risk factors were entered as explanatory variables. Coefficients from such regression models are equivalent to those obtained by proportional hazards regression ${ }^{22}$ and estimate the logarithm of the rate ratio per unit increase in an explanatory variable. In this instance these are mortality ratios and are all adjusted for the variables matched in the design (age and height in the first study, age and $F E V_{1}$ in the second), in addition to other explanatory variables in the model.

In order to compare the relative importance of various risk factors as predictors of mortality in the whole group of non-smoking men, the distribution of each risk factor was adjusted for age and standardised to a common scale. This was achieved by calculating the difference between the measurement for each man and the mean of measurements for all lifelong non-smokers of the same single year of age in the study population, and dividing this by the standard deviation of measurements for men of the same age. These age specific " $z$ scores" were then ranked and the upper, middle, and lower thirds of the distribution were used in the analysis. The use of these age adjusted tertiles removed any confounding effect of age upon the relationship between the level of each risk factor and subsequent mortality.

\section{Results}

\section{STUDY POPULATION}

Among 18403 men aged 40-64 years at examination, $3455(19 \%)$ denied ever having smoked cigarettes, cigars, or a pipe. Three men (all of whom died during follow up) had no spirometric measurements recorded. Among the remaining 3452 men there were 445 deaths during 60084 person-years of follow up (average 17.4 years per man). These included 11 deaths from lung cancer.

The entry examinations preceded the adoption of internationally accepted criteria for definition of spirometric indices. ${ }^{23}$ However, a sample of the original spirograms from lifelong non-smokers was inspected as part of another study. The sum of the $\mathrm{FEV}_{1}$ and FVC from each of the two "best tests", as defined by the American Thoracic Society criteria, ${ }^{23}$ were within $5 \%$ of each other in $84 \%(73 / 87)$ spirograms, within $7 \%$ in $91 \%$ (79/87), and within $10 \%$ in $98 \%(85 / 87)$.

Forced expiratory volume in one second $\left(\mathrm{FEV}_{1}\right)$ was strongly related to age, height, and employment grade, which together explained $31 \%$ of the variance. The effect of employment grade was mainly due to a difference of $300 \mathrm{ml}$ in mean age-height adjusted $\mathrm{FEV}_{1}$ between the 2717 men in "high" grades (administrative, professional, and executive posts) and the 571 in "low" grades (clerical and messenger posts). One hundred and sixty four men in the British Council and Diplomatic Service (excluded from the above grade categories) had similar adjusted $\mathrm{FEV}_{1}$ to those in the "high" grades. After adjustment for age, height, and grade, there remained considerable individual variation in $\mathrm{FEV}_{1}$ (residual standard deviation $=573 \mathrm{ml}$ ).

\section{HEIGHT MATCHED CASE-CONTROL ANALYSES}

One or more controls of the same age and height were available for $408(92 \%)$ of the 445 deaths. Overall, there were 2874 controls, an average of seven per matched case. The ventilatory function of the matched cases was not extreme: $320(78 \%)$ had an $\mathrm{FEV}_{1}$ in the range 2.5-4.0 litres.

The relationship between ventilatory function and all cause mortality was almost identical, whether $\mathrm{FEV}_{1}$ or FVC was used in the analysis. The association was marginally stronger for $\mathrm{FEV}_{1}$ (rate ratio per 1 litre decrease $=1.52,95 \%$ confidence interval $1 \cdot 27-1 \cdot 83, \chi^{2}=20 \cdot 1, \mathrm{df}=1$ ) than for FVC (rate ratio per 1 litre decline $=1.51$, $95 \%$ CI $\left.1 \cdot 25-1 \cdot 82, \chi^{2}=19 \cdot 3, \mathrm{df}=1\right)$. The ratio $\mathrm{FEV}_{1} / \mathrm{FVC}$ was therefore not associated with overall mortality, although it was a significant predictor of death from respiratory disease (rate ratio per $10 \%$ decline $=2 \cdot 12,95 \%$ CI $1 \cdot 19-3 \cdot 77$, $\left.\chi^{2}=8 \cdot 74, \mathrm{df}=1\right)$.

Table I shows the rate ratios (per litre decrease in $\mathrm{FEV}_{1}$ ) for various causes of death. Reduced levels of $\mathrm{FEV}_{1}$ (adjusted for age and height by matching) were associated with increased mortality for all groups of causes studied. This excess was most marked for respiratory disease, 
but remained highly significant when nonrespiratory causes were considered. Among the non-respiratory causes, the association with cancer deaths was weakest, and that with noncancer, non-circulatory deaths was strongest. However, this heterogeneity of rate ratios could readily be due to chance $\left(\chi^{2}\right.$ for interaction $=0.71$, $\mathrm{df}=2$ ). When circulatory deaths were further subdivided, reduced $\mathrm{FEV}_{1}$ was significantly associated with both coronary and non-coronary mortality. Fatal strokes accounted for half of the latter category.

The effect of $\mathrm{FEV}_{1}$ on all cause mortality was examined by age at death and duration of follow up. There was no substantial variation in the rate ratios for death above and below 70 years $\left(\chi^{2}\right.$ for interaction $=0 \cdot 20, \mathrm{df}=1)$. The association of $\mathrm{FEV}_{1}$ with death in the first 10 years of follow up (rate ratio per litre decrease $=1.94,95 \%$ CI $1 \cdot 46-2.57)$ was stronger than with later deaths $(1.28,1.01-1.64)$, the interaction being significant $\left(\chi^{2}=4 \cdot 90, \mathrm{df}=1\right)$.

Table II shows the mortality rate ratios (per 1 litre decrease in $\mathrm{FEV}_{1}$ ) for circulatory diseases, before and after adjustment for known cardiovascular risk factors. Adjustment for employment grade (in five categories) increased the coefficient for $\mathrm{FEV}_{1}$ very slightly. This was because matching for age and height in the design effectively removed grade differences in circulatory disease mortality. Further adjustment for systolic blood pressure, plasma cholesterol and body weight did not substantially alter the effect of $\mathrm{FEV}_{1}$.

Inclusion of prevalent coronary heart disease as an additional covariate reduced the independent effect of $\mathrm{FEV}_{1}$ (table II) but the latter remained significant at the $5 \%$ level $\left(\chi^{2}=3 \cdot 99, \mathrm{df}=1\right)$. The association of $\mathrm{FEV}_{1}$ with circulatory mortality was not confined to those with prevalent coronary heart disease $\left(\chi^{2}\right.$ for interaction $\left.=0.09, \mathrm{df}=1\right)$. Among those with no prevalent heart disease, the

Table I Rate ratio estimates ${ }^{a}$ (with $95 \%$ confidence intervals) for mortality from various causes associated with decrease in FEV for age and height.

\begin{tabular}{|c|c|c|c|c|c|}
\hline \multirow{2}{*}{$\begin{array}{l}\text { Cause of death } \\
\text { All causes }\end{array}$} & \multirow{2}{*}{$\begin{array}{l}\begin{array}{l}\text { Cases } \\
(n)\end{array} \\
408\end{array}$} & \multirow{2}{*}{$\frac{\begin{array}{l}\text { Controls } \\
(n)\end{array}}{2874}$} & \multicolumn{2}{|c|}{$\begin{array}{l}\text { Rate ratio }(95 \% \mathrm{CI}) \text { per } \\
\text { litre decrease in } \mathrm{FEV} \mathrm{V}_{1}\end{array}$} & \multirow{2}{*}{$\frac{\chi^{2}(1 d f)}{20 \cdot 1}$} \\
\hline & & & 1.52 & $(1 \cdot 27-1 \cdot 83)$ & \\
\hline $\begin{array}{l}\text { Respiratory disease } \\
\text { Non-respiratory causes }\end{array}$ & $\begin{array}{r}20 \\
388\end{array}$ & $\begin{array}{r}78 \\
2796\end{array}$ & $\begin{array}{l}4 \cdot 16 \\
1 \cdot 44\end{array}$ & $\begin{array}{l}(1 \cdot 69-10 \cdot 2) \\
(1 \cdot 19-1 \cdot 73)\end{array}$ & $\begin{array}{l}12 \cdot 5 \\
13 \cdot 9\end{array}$ \\
\hline $\begin{array}{l}\text { Malignant neoplasms } \\
\text { Circulatory disease } \\
\text { Other non-respiratory causes }\end{array}$ & $\begin{array}{r}105 \\
236 \\
47\end{array}$ & $\begin{array}{r}826 \\
1649 \\
321\end{array}$ & $\begin{array}{l}1 \cdot 27 \\
1.49 \\
1 \cdot 60\end{array}$ & $\begin{array}{l}(0 \cdot 89-1 \cdot 82) \\
(1 \cdot 16-1 \cdot 91) \\
(0 \cdot 96-2 \cdot 66)\end{array}$ & $\begin{array}{l}1 \cdot 70 \\
9 \cdot 78 \\
3 \cdot 14\end{array}$ \\
\hline $\begin{array}{l}\text { Coronary heart disease } \\
\text { Other circulatory disease }\end{array}$ & $\begin{array}{r}171 \\
65\end{array}$ & $\begin{array}{r}1225 \\
424\end{array}$ & $\begin{array}{l}1.38 \\
1.87\end{array}$ & $\begin{array}{l}(1 \cdot 04-1 \cdot 84) \\
(1 \cdot 13-3 \cdot 10)\end{array}$ & $\begin{array}{l}4.92 \\
5.91\end{array}$ \\
\hline
\end{tabular}

$b$ Matched for age (single years) and height (nearest $1.3 \mathrm{~cm}$ ) adjusted rate ratio per litre decline in $\mathrm{FEV}_{1}$ was $1.30(95 \%$ CI 0.96-1.76).

When 45 cases and 233 controls with a history of phlegm, wheeze, or exertional dyspnoea were removed from the analysis, the relationship between $\mathrm{FEV}_{1}$ and circulatory death was strenghtened: rate ratio per litre decrease $=1.55$ (95\% CI 1.16-2.08), compared to 1.49 among all case-control sets.

FEV $_{1}$ MATCHED CASE-CONTROL ANALYSES

One or more controls of the same age and FEV were available for $397(89 \%)$ of the 445 deaths. Overall, there were 2536 controls, an average of 6.4 per matched case.

Table III presents the rate ratios per $10 \mathrm{~cm}$ decrease in height for all causes of death and mortality from specific causes, adjusted for age and $\mathrm{FEV}_{1}$ by matching. The effect of height on mortality was generally weak and was nonsignificant throughout. There was virtually no independent influence of height on mortality from circulatory disease at any given age and measured $\mathrm{FEV}_{1}$

The effect of employment grade upon mortality after adjustment for age and $\mathrm{FEV}_{1}$ by matching was largely confined to respiratory deaths. Comparing "low" grades to "high" grades, the mortality rate ratio was $1.10(95 \%$ confidence interval 0.83-1.47) for all causes of death, 1.06 $(0.79-1.42)$ for non-respiratory causes, and 3.78 $(0 \cdot 74-19 \cdot 3)$ for respiratory disease.

RELATIVE IMPORTANCE OF FEV I AS A PREDICTOR OF MORTALITY

The importance of measured $\mathrm{FEV}_{1}$ and height adjusted $\mathrm{FEV}_{1}$ as predictors of mortality in the whole population of 3452 lifelong non-smokers was explored by comparing the death rates in age adjusted tertiles of various risk factors measured at the entry examination. Table IV shows that differentials in all cause mortality across the tertiles of height adjusted $\mathrm{FEV}_{1}$ were greater than the equivalent differentials for height, body mass index, or plasma cholesterol. The analysis of case-control sets matched for $\mathrm{FEV}_{1}$ suggested that height had little effect upon mortality if FEV was known. The convention of adjusting ventilatory function for height may therefore be considered as "overmatching" which would tend to reduce power to detect effects of reduced $\mathrm{FEV}_{1}$ on mortality. When $\mathrm{FEV}_{1}$ unadjusted for height was considered, the differential across age adjusted tertiles was greater than for height adjusted $\mathrm{FEV}_{1}$, and approached the magnitude of the trend for systolic blood pressure, the most powerful single predictor of mortality among these lifelong non-smokers.
Table II Rate ratio estimates (with 95\% confidence intervals) for mortality from circulatory disease associated with decrease in $F E V_{1}$, before decrease in $F E V_{1}$, before
and after adjustment ${ }^{a}$ for various cardiovascular risk factors

\begin{tabular}{|c|c|c|c|c|c|}
\hline \multirow{3}{*}{$\begin{array}{l}\text { Risk factor } \\
\text { Employment grade }\end{array}$} & \multirow{3}{*}{$\begin{array}{l}\text { Cases } \\
(n)\end{array}$} & \multirow{3}{*}{$\frac{\text { Controls }^{b}}{(n)}$} & \multicolumn{3}{|c|}{ Rate ratio $(95 \% C I)$ per litre decrease in $F E V_{I}$} \\
\hline & & & before adjustment ${ }^{a}$ & \multicolumn{2}{|c|}{ after adjustment } \\
\hline & & & $1.49(1.16-1.91)$ & 1.50 & $(1 \cdot 17-1 \cdot 94)$ \\
\hline $\begin{array}{l}\text { Grade, systolic blood pressure, } \\
\text { plasma cholesterol, body weight }\end{array}$ & 226 & 1536 & $1.39 \quad(1.08-1.80)$ & $1 \cdot 37$ & $(1.04-1 \cdot 79)$ \\
\hline $\begin{array}{l}\text { Above four factors plus } \\
\text { prevalent coronary heart disease }\end{array}$ & 225 & 1530 & $1.42(1 \cdot 10-1 \cdot 83)$ & 1.33 & $(1.01-1.75)$ \\
\hline
\end{tabular}




\section{Discussion}

The restriction of this analysis to lifelong nonsmokers was based upon self reported smoking habit, and it is likely that some misclassification of smokers as non-smokers occured. However, it is unlikely that such errors were common enough to generate an association between ventilatory function and mortality of the magnitude that was observed. It is possible that spirometric performance was influenced by preclinical disease present at examination, ${ }^{24}$ but the effect of $\mathrm{FEV}_{1}$ on mortality was found even after 10 years follow up and also among subjects with no respiratory symptoms.

The observed association between reduced ventilatory function and risk of death in this cohort is therefore more likely to be real than spurious. Follow up was limited to fatal events, so it is not possible to distinguish whether the excess mortality among the men with low levels of $\mathrm{FEV}_{1}$ was due to increased incidence of disease or to greater case fatality. The association of reduced ventilatory function with mortality was not confined to any specific cause of death, and it is likely that no single mechanism accounts for all these relationships.

Early interest in the relationship between vital capacity and cardiovascular disease was stimulated by the hypothesis that ventilatory function might be an indicator of physical activity or physical fitness, ${ }^{25}$ both of which have been found to predict mortality. ${ }^{26}{ }^{27}$ However, habitual activity is not an important determinant of ventilatory function in adults ${ }^{28}$ and forced vital capacity is a poor predictor of physical fitness, ${ }^{29}$ so it is unlikely that these mechanisms could account for more than a small part of the association between reduced $\mathrm{FEV}_{1}$ and all cause mortality.

Table III Rate ratio estimates ${ }^{a}$ (with $95 \%$ confidence intervals) for mortality from various causes associated with decrease in height, among cases and controls matched for age and $F E V_{1}$.

\begin{tabular}{|c|c|c|c|c|c|}
\hline \multirow{2}{*}{$\begin{array}{l}\text { Cause of death } \\
\text { All causes }\end{array}$} & \multirow{2}{*}{$\begin{array}{l}\begin{array}{l}\text { Cases } \\
(n)\end{array} \\
397\end{array}$} & \multirow{2}{*}{$\begin{array}{l}\begin{array}{l}\text { Controls } \\
(n)\end{array} \\
2536\end{array}$} & \multicolumn{2}{|c|}{$\begin{array}{l}\text { Rate ratio }(95 \% \mathrm{CI}) \text { per } \\
10 \mathrm{~cm} \text { decrease in height }\end{array}$} & \multirow{2}{*}{$\frac{\chi^{2}(I d f)}{0.94}$} \\
\hline & & & $1 \cdot 10$ & $(0 \cdot 91-1 \cdot 32)$ & \\
\hline $\begin{array}{l}\text { Respiratory disease } \\
\text { Non-respiratory causes }\end{array}$ & $\begin{array}{r}16 \\
381\end{array}$ & $\begin{array}{r}54 \\
2482\end{array}$ & $\begin{array}{l}1.33 \\
1.09\end{array}$ & $\begin{array}{l}(0 \cdot 56-3 \cdot 12) \\
(0 \cdot 90-1 \cdot 31)\end{array}$ & $\begin{array}{l}0.43 \\
0.72\end{array}$ \\
\hline $\begin{array}{l}\text { Malignant neoplasms } \\
\text { Circulatory disease } \\
\text { Other non-respiratory causes }\end{array}$ & $\begin{array}{r}106 \\
231 \\
44\end{array}$ & $\begin{array}{r}792 \\
1364 \\
326\end{array}$ & $\begin{array}{l}1.22 \\
0.99 \\
1.22\end{array}$ & $\begin{array}{l}(0 \cdot 87-1 \cdot 72) \\
(0 \cdot 88-1 \cdot 14) \\
(0 \cdot 71-2 \cdot 10)\end{array}$ & $\begin{array}{l}1.30 \\
0.00 \\
0.55\end{array}$ \\
\hline $\begin{array}{l}\text { Coronary heart disease } \\
\text { Other circulatory disease }\end{array}$ & $\begin{array}{r}172 \\
59\end{array}$ & $\begin{array}{r}1068 \\
296\end{array}$ & $\begin{array}{l}1.00 \\
0.98\end{array}$ & $\begin{array}{l}(0 \cdot 86-1 \cdot 16) \\
(0 \cdot 76-1 \cdot 28)\end{array}$ & $\begin{array}{l}0.00 \\
0.01\end{array}$ \\
\hline
\end{tabular}

Matched analysis by conditional logistic regression

Matched for age (single years) and $\mathrm{FEV}_{1}$ (nearest $100 \mathrm{ml}$ )
Diminished lung function may be an indicator of environmental influences upon mortality, or it may be implicated directly in the causal pathway, particularly as a determinant of case fatality. Little is known of the constitutional or environmental determinants of ventilatory function among lifelong non-smokers, and the present study suggests that this forms an important agenda for future research. In general terms, $\mathrm{FEV}_{1}$ may be affected either by the development of the lung or the occurrence of airway obstruction. In this male cohort, as among the mostly female lifelong non-smokers in the Copenhagen City Heart Study, ${ }^{14}$ the ratio of $\mathrm{FEV}_{1}$ to $\mathrm{FVC}$ was relatively unimportant as a predictor of death, suggesting that the capacity of the lungs, which is in part determined by stature, may be the more important variable.

The analysis of case-control sets matched for age and $\mathrm{FEV}_{1}$ supported the suggestion that the association between height and coronary heart disease is explained by lower absolute levels of ventilatory capacity in shorter men. ${ }^{18}$ This conclusion also applied to other causes of death. The convention of adjusting lung function measurements for height in epidemiological studies may deserve reconsideration, particularly where the prediction of subsequent morbidity or mortality is of interest. Height has attracted epidemiological interest as a marker of early dietary and environmental influences upon subsequent disease outcomes. ${ }^{17}$ The findings here suggest that such influences, if they exist, may be more adequately indicated by the ventilatory function of the adult lung. Respiratory function also offers a plausible mechanism for a causal relationship between experiences in childhood and mortality in middle age. ${ }^{30}$

When compared in a standardised way to widely recognised risk factors for premature death, $\mathrm{FEV}_{1}$ appeared to be a powerful predictor of subsequent mortality. Hypertension, obesity, and raised plasma cholesterol are considered of clinical relevance because they are potentially reversible following appropriate treatment or modifications to lifestyle. However, the reversibility of the associated risk may be less impressive: for example, treatment of hypertension results in only a partial reduction of the excess mortality. ${ }^{31}$ Prevention is likely to be more succesful if the emergence of an adverse combination of risk factors can be avoided. Potentially remediable influences upon the development of the lung in childhood and the rate of decline of ventilatory capacity in adult non-
Table IV Mortality rates (per 1000 personyears) for all 3452

lifelong non-smokers by age adjusted tertile of various cardiovascular risk factors, height, $F E V_{1}$ and height adjusted FEV

\begin{tabular}{|c|c|c|c|c|c|c|c|}
\hline $\begin{array}{l}\text { Cause of } \\
\text { death }\end{array}$ & $\begin{array}{l}\text { Tertile } \\
\text { of risk }\end{array}$ & $\begin{array}{l}\text { Systolic } \\
\text { blood pressure }\end{array}$ & $\begin{array}{l}\text { Plasma } \\
\text { cholesterol }\end{array}$ & $\begin{array}{l}\text { Body mass } \\
\text { index }\end{array}$ & Height & $\begin{array}{l}\text { Height } \\
\text { adjusted FEV }\end{array}$ & $\begin{array}{l}\text { Unadjusted } \\
F E V_{1}\end{array}$ \\
\hline All causes & $\begin{array}{l}\text { Low risk } \\
\text { Middle } \\
\text { High risk }\end{array}$ & $\begin{array}{l}5 \cdot 2 \\
7.4 \\
9.9\end{array}$ & $\begin{array}{l}7.0 \\
6 \cdot 2 \\
8.8\end{array}$ & $\begin{array}{l}6 \cdot 1 \\
7 \cdot 4 \\
8 \cdot 8\end{array}$ & $\begin{array}{l}6 \cdot 2 \\
7 \cdot 3 \\
8 \cdot 6\end{array}$ & $\begin{array}{l}5 \cdot 9 \\
7 \cdot 1 \\
9 \cdot 1\end{array}$ & $\begin{array}{l}5 \cdot 1 \\
7.9 \\
9 \cdot 2\end{array}$ \\
\hline $\begin{array}{l}\text { Malignant } \\
\text { neoplasms }\end{array}$ & $\begin{array}{l}\text { Low risk } \\
\text { Middle } \\
\text { High risk }\end{array}$ & $\begin{array}{l}1.4 \\
1.7 \\
2.4\end{array}$ & $\begin{array}{l}1.8 \\
1.7 \\
1.8\end{array}$ & $\begin{array}{l}1.5 \\
1.8 \\
2.3\end{array}$ & $\begin{array}{l}1.9 \\
2.1 \\
1.6\end{array}$ & $\begin{array}{l}1 \cdot 4 \\
2 \cdot 2 \\
2 \cdot 0\end{array}$ & $\begin{array}{l}1 \cdot 0 \\
2 \cdot 4 \\
2 \cdot 1\end{array}$ \\
\hline $\begin{array}{l}\text { Circulatory } \\
\text { disease }\end{array}$ & $\begin{array}{l}\text { Low risk } \\
\text { Middle } \\
\text { High risk }\end{array}$ & $\begin{array}{l}2 \cdot 6 \\
4 \cdot 4 \\
6 \cdot 1\end{array}$ & $\begin{array}{l}3.9 \\
3.4 \\
5 \cdot 7\end{array}$ & $\begin{array}{l}3 \cdot 1 \\
4 \cdot 5 \\
5 \cdot 4\end{array}$ & $\begin{array}{l}3 \cdot 6 \\
4 \cdot 6 \\
4 \cdot 8\end{array}$ & $\begin{array}{l}3.7 \\
3.8 \\
5.4\end{array}$ & $\begin{array}{l}3 \cdot 5 \\
4 \cdot 3 \\
5 \cdot 2\end{array}$ \\
\hline Other causes ${ }^{b}$ & $\begin{array}{l}\text { Low risk } \\
\text { Middle } \\
\text { High risk } \\
\end{array}$ & $\begin{array}{l}1 \cdot 1 \\
1.2 \\
1.4\end{array}$ & $\begin{array}{l}1.3 \\
1.0 \\
1.4\end{array}$ & $\begin{array}{l}1.5 \\
1.1 \\
1.1\end{array}$ & $\begin{array}{l}1.0 \\
0.7 \\
2.0\end{array}$ & $\begin{array}{l}0.8 \\
1.1 \\
1.7\end{array}$ & $\begin{array}{l}0.6 \\
1.2 \\
1.9\end{array}$ \\
\hline
\end{tabular}

a"Low risk" groups are the lowest age adjusted tertiles of systolic blood pressure, plasma cholesterol and body mass index, and highest age adjusted tertiles of height, adjusted and unadjusted $F_{1}$ 
smokers may have long term consequences of considerable importance to public health.

I am grateful to Professor G Rose for encouraging me to analyse 18 mortality data from the Whitehall study, and for his helpful comments upon the paper.

1 Higgins MW, Keller JB.Predictors of mortality in the adult population of Tecumseh. Respiratory symptoms, chronic population of Tecumseh. Respiratory symptoms, chronch respiratory disease and ventilato

2 Ashley F, Kannel WB, Sorlie PD, Masson R. Pulmonary function: relation to aging, cigarette habit and mortality. Ann Intern Med 1975; 82: 739-45.

3 Freidman GD, Klatsky AL, Siegelaub AB. Lung function and risk of myocardial infarction and sudden cardiac death. $N$ Engl f Med 1976; 294: 1071-5.

4 Beaty TH, Cohen BH, Newill CA, Menkes HA, Diamond EL, Chen CJ. Impaired pulmonary function as a risk factor for mortality. Am 7 Epidemiol 1982; 116: 102-13.

5 Peto R, Speizer FE, Cochrane AL, et al. The relevance in adults of air-flow obstruction, but not of mucus hypersecretion to mortality from chronic lung disease. $A m$ Rev Respir Dis 1983; 128: 491-500.

6 Kryzanowski $M$, Wysocki $M$. The relation of thirteen-year mortaity to ventilatory impairment and other respiratory mortaity to ventilatory impaim. Int f Epidemiol 1986; 15 : 56-64.

7 Persson C, Bengtsson C, Lapidus L, Rybo E, Thiringer G Wedel H. Peak expiratory flow rate and risk of cardiovascular disease and death: a 12-year follow-up of participants in the population study of women in Gothenburg, Sweden. Am $₹$ Epidemiol 1986; 124: 942-8.

8 Annesi I, Kauffmann F. Is respiratory mucus hypersecretion really an innocent disorder? Am Rev Respir Dis 1986; 134: 688-93.

9 Farchi G, Menotti A, Conti S. Coronary risk factors and survival probability from coronary and other causes of death Am 7 Epidemiol 1987; 126: 400-8.

10 Ebi-Kryston KI, Hawthorne VM, Rose G, et al. Breathlessness, chronic bronchitis and reduced pulmonary function as predictors of cardiovascular disease mortality among men in England, Scotland and the United States. Int ๆ Epidemiol 1989; 18: 84-8.

11 Marcus EB, Curb JD, MacLean CJ, Reed DM, Yano K Pulmonary function as a predictor of coronary hear disease. Am 7 Epidemiol 1989; 129: 97-104.

12 Beaty TH, Newill CA, Cohen BH, Tockman MS, Bryan SH Spurgeon HA. Effects of pulmonary function on mortality. $\exists$ Chronic Dis 1985; 38: 703-10.

13 Kannel WB, Hubert $H$, Lew EA. Vital capacity as predictor of cardiovascular disease: the Framingham study Am Heart $¥$ 1983; 105: 311-5.
14 Lange P, Nyboe J, Appleyard M, Jensen G, Schnohr P. Spirometric findings and mortality in never-smokers. $f$ Clin Epidemiol 1990; 43: 867-73.

15 Anderson HR, Vallance P, Bland JM, Nohl F, Ebrahim S Prospective study of mortality associated with chronic lung disease and smoking in Papua New Guinea. Int $₹$ Epidemiol disease and smokin

16 Waaler $\mathrm{H}$. Height, weight and mortality. The Norwegian experience. Acta Med Scand 1984 [Suppl]; 679: 1-56.

17 Marmot MG, Shipley MJ, Rose G. Inequalities in deathMarmot MG, Shipley MJ, Rose G. Inequalities in deathspecific

18 Walker M, Shaper AG, Phillips AN, Cook DG. Short stature, lung function and risk of a heart attack. Int $\mathscr{f}$ stature, lung function and

19 Reid DD, Brett GZ, Hamilton PJS, Jarrett RJ, Keen H, Rose G. Cardiorespiratory disease and diabetes among middle-aged male civil servants. A study of screening and intervention. Lancet 1974; i: 469-72.

20 SAS Institute Inc. SAS User's Guide: Basics, Version Edition. Cary, NC: SAS Institute, 1985.

21 Epidemiological Resources Inc. EGRET: Epidemiological Graphics, Estimation and Testing. Seattle, WA Epidemiological Resources Inc, 1988.

22 Breslow NE, Day NE. Statistical methods in cancer research. Volume II: The design and analysis of cohort studies. Lyon: International Agency for Research on Cancer, 1987: 204-6.

23 American Thoracic Society Statement. Snowbird workshop on standardisation of spirometry. Am Rev Respir Dis 1979; 119: 831-8.

24 Kannel WB, Seidman JM, Fercho W, Castelli WP. Vita capacity and congestive heart failure: the Framingham study Circulation 1974; 49: 1160-6.

25 Kannel WB. Habitual level of physical activity and risk of . coronary heart dise

26 Paffenter RS, Hyde RT, Wing AL, Hsieh CC. Physical activity, all-cause mortality and longevity of college alumni. activity, all-cause mortality and 13 .

27 Blai SN, Ked HW, Paffenberger RS, Clark DG, Cooper KH Gibbons LW. Physical fitness and all-cause mortality. AH, Gibbons $L W$. Physical fitness and an -cause mortality. A prospective study $262: 2395-401$.

28 B Physical activity of occupation and cigarette smoking: relationship to of occupation and cigarette smospiratory relationship to ventilatory function and $12-22$.

symptoms. Arch Environ Health 1965; 10: 312-22. Wilso PWF. Surrogate measures of physical activity and physica fitness. Evidence for sedentary traits of resting tachycardia obesity, and low vital capacity. Am ₹ Epidemiol 1989; 129. $1145-6$.

30 Barker DJP, Osmond C, Law CM. The intrauterine and early postnatal origins of cardiovascular disease and chronic bronchitis. I Epidemiol Community Health 1989; 43 237-40.

31 MacMahon S, Cutler JA, Stamler J. Antihypertensive drug treatment. Potential, expected and observed effects on stroke and on coronary heart disease. Hypertension 1989; 13[suppl I]: I45-50. 